\title{
Stage IIIB Vulvar Cancer AJCC v7
}

National Cancer Institute

\section{Source}

National Cancer Institute. Stage IIIB Vulvar Cancer AJCC v7. NCI Thesaurus. Code C87004.

Stage IIIB includes: (T1/T2, N2a/N2b, M0). T1: Invasive vulvar cancer confined to the vulva or perineum. T2: Vulvar cancer with tumor of any size with extension to adjacent perineal structures (lower/distal 1/3 urethra, lower/distal 1/3 vagina, anal involvement). N2a: Vulvar cancer with three or more lymph node metastases each measuring $5 \mathrm{~mm}$ or less. N2b: Vulvar cancer with two or more lymph node metastases measuring $5 \mathrm{~mm}$ or greater. M0: No distant metastasis. (AJCC 7th ed.) 